\title{
A FICÇÃO CIENTÍFICA E O ESTRANHAMENTO COGNITIVO NO ENSINO DE CIÊNCIAS: ESTUDOS CRÍTICOS E PROPOSTAS DE SALA DE AULA*
}

\section{Science fiction and the cognitive estrangement in science teaching: critical studies and proposals for the classroom}

Luís Paulo Piassi ${ }^{1}$

Resumo: Este trabalho, partindo da apresentação de propostas de ensino de ciências com o uso da ficção científica e fundamentando-se em referenciais dos estudos literários críticos sobre o gênero, objetiva argumentar que sua maior contribuição para a educação científica não se situa nem na precisão científica, nem na qualidade didática e nem mesmo no potencial lúdico que esse tipo de narrativa desperta. Sem desconsiderar a importância desses aspectos, mostramos que o sentido de levar a ficção científica para as aulas de ciências está nos mecanismos de produção ficcional que, por características que the são próprias, envolve um modo especial de raciocinar sobre o mundo natural. Tais mecanismos baseiam-se em conjecturas que promovem o chamado estranhamento cognitivo capaz de promover, nos estudantes, a problematização que pode ser o ponto de partida para uma abordagem crítica, não apenas de conceitos e leis, mas, também, de suas implicações e motivações epistemológicas e socioculturais.

Palavras-chave: Ensino de ciências. Ficção científica. Literatura. Estranhamento cognitivo.

\begin{abstract}
This paper is based on the proposal for teaching science through the use of science fiction and relies on references to literary critics of the genre, arguing that the greatest contribution to science education is not situated either in scientific precision, nor in didactic intentions nor even in the potential play this kind of narrative brings. Without disregarding the importance of these aspects, we argue that the main reason for bringing science fiction to science classes derives from the mechanisms of producing fiction that involves a special way of thinking about the natural world. Such mechanisms are based on assumptions that promote a so-called cognitive estrangement, which is able to promote in students reasoning as the starting point for a critical approach for teaching not only concepts and laws, but also epistemological and sociocultural implications and motivations.
\end{abstract}

Keywords: Science teaching. Science fiction. Literature. Cognitive estrangement.

\footnotetext{
* Reformulação, ampliada em seus aspectos de análise teórica, do capítulo 'Ficção científica nas aulas de física', (PINTO, 2010). Ambos os trabalhos são baseados em revisão do texto de Piassi (2007).

${ }^{1}$ Escola de Artes, Ciências e Humanidades, Universidade de São Paulo. Rua Arlindo Bettio, n. 1000, Vila

Guariciaba. São Paulo, SP, Brasil. 03.828-000.lppiassi@usp.br
} 


\section{Introdução: ficção, ciência e sociedade}

A influência das conquistas técnicas, como aponta Hémery (1993), abrange desde a antiguidade até os tempos atuais, e, em todos esses tempos, alterou drasticamente a base econômica da sociedade. Isso vale para a invenção do arado e para o domínio do fogo, na préhistória, até a invenção do transistor e da inseminação artificial no século XX. A intensidade desse processo, porém, foi variável ao longo da história, assim como sua percepção. Não há dúvida, porém, de que é a partir da revolução industrial e, sobretudo, desde meados do século XIX, que a ciência e seus produtos vêm adquirindo papel e visibilidade crescentes nas relações sociais, econômicas e culturais. Com isso, a influência da ciência nas diversas manifestações culturais começa a ser, igualmente, cada vez mais intensa. A partir do século XIX, muitas obras literárias passam a incorporar sistematicamente ideias oriundas da ciência. $\mathrm{Na}$ passagem do século XVIII para o XIX, encontramos um acúmulo de condições, dadas pela Revolução Francesa e pela Revolução Industrial, que permitiram o surgimento desse gênero literário hoje conhecido como ficção científica. Segundo Oliveira (2004, p. 1):

[...] o desenvolvimento tecnocientífico como desencadeador de mudanças, o sujeito como modo de ser do homem, e a mudança como possibilidade de sonhar com o futuro - forneceram o terreno fértil para a narrativa de ficção científica.

Por muitos considerado um marco, Frankenstein, de Mary Shelley (1973), publicado em 1816, talvez seja a primeira obra a captar com clareza a preocupação com os caminhos trilhados pelo progresso científico, sinal de que a ciência e suas consequências, tantos as desejáveis quanto as nem tanto, estavam ingressando na pauta das indagações fundamentais sobre a vida. A associação da ciência com o mito de Prometeu, explícita no título do romance de Shelley (1973), foi reencenada, inúmeras vezes, dos mais variados ângulos na ficção do século XX, sobretudo após o advento da bomba atômica, com sua aterradora realidade concretizada em Hiroshima e Nagasaki e suas não menos assustadoras possibilidades imagináveis.

A ficção científica moderna começa a se estabelecer a partir do escritor francês Jules Verne $(2003,2004)$, que escreveu um número imenso de obras, como '20.000 léguas submarinas' e 'Viagem ao centro da Terra', entre outras, e do inglês H. G. Wells (1991, 2000, 2001), que escreveu histórias como 'A máquina do tempo', 'A guerra dos mundos', e 'O homem invisível', entre muitas outras. Estes dois autores influenciaram decisivamente as obras subsequentes do gênero que viria a receber o nome de ficção científica, difundido pelo editor norte-americano Hugo Gernsback já no século XX (CAUSO, 2003, p. 53-54; RABKIN, 1977, p. 119). Interessante notar que, apesar de possuírem em comum a inspiração na ciência, as obras desses dois autores são marcantemente diferentes. O fato é que, tanto em temática quanto em estilo, os dois precursores da ficção científica foram fundamentais na inauguração de um novo gênero. As obras de Verne são histórias para divertir e maravilhar os leitores com as possibilidades de um futuro excitante, enquanto as de Wells empregam conjecturas científicas mais ousadas e fantasiosas para questionar aspectos da sociedade e comportamento humano. Segundo Parrinder (1980), Verne criticava Wells por não se ater aos preceitos da ciência, por caminhar por impossibilidades e por contradições com o conhecimento científico. O interesse de Wells, 
porém, ia além disso; e, dentro do meio literário, se houve outras críticas ao seu trabalho, foi mais pela sujeição da obra literária ao seu engajamento político do que pela forma com que tratou a ciência em seus romances (BORGES, 1991).

E é justamente com a publicação de contos voltados para um público popular - sobretudo adolescentes - que a ficção científica ganha impulso nos anos 1920; e é pelas mãos de Hugo Gernsback e de Joseph Campbell, editores de algumas das inúmeras publicações em papel jornal vendidas aos milhares em bancas de jornais, que a ficção científica adquire não só seu nome, mas, também, uma identidade e uma qualidade que lhe conferirão características singulares como forma de criação literária (ASIMOV, 1979, 1984). Dessa origem literária, a ficção científica se espalhou por diversos meios, como: filmes de cinema, produções televisivas, histórias em quadrinhos, desenhos animados e, mais recentemente, jogos de interpretação de papéis (RPG) e jogos de computador (OLIVEIRA, 2004). A indústria cinematográfica e televisiva norte-americana popularizou o gênero mundialmente através de séries como 'Jornada nas estrelas' (2005), e filmes de enorme sucesso como 'Guerra nas estrelas' (STAR..., 2006), entre inúmeros outros. Nesse trajeto, houve momentos de grande interesse e tempos de declínio da ficção científica. Eventos que colocaram a ciência e suas realizações em evidência contribuíram para momentos de auge no gênero. Augusto (1977), por exemplo, comenta a influência, no pós Segunda Guerra Mundial, dos temas espaciais e fantásticos em séries de histórias em quadrinhos que não guardavam qualquer relação com a ficção científica. Ao lado do entusiasmo pelas conquistas espaciais, essa época também foi marcada pelo temor das bombas atômicas, sentimento retratado em milhares de páginas e quilômetros de celuloide da ficção científica dessa época. Portanto, longe de ser um gênero que se ocupa de elucubrações vazias sobre o futuro, a ficção científica veicula, como todas as formas de arte, as preocupações do presente, em particular, aquelas vinculadas às mudanças sociais trazidas pela ciência e pela técnica.

A ficção científica, como cultura de massas disseminada entre crianças e adolescentes, é certamente um dos elementos da cultura primeira a que se refere Snyders (1988), um elemento que a escola não pode ignorar, como destacam Shaw e Dybdahl (2000). Ao mesmo tempo, assim como os próprios conhecimentos científicos, muitas das manifestações da ficção científica representam aquilo que podemos chamar de cultura elaborada. Um modo de entender isso vem da característica fundamental que Snyders (1988, p. 68) atribui à cultura:

A cultura não é uma soma de conhecimentos, um conjunto de obras a admirar, amar, degustar, mas simultaneamente obras e um modo de vida e a procura de novos modos de vida; são os modos de vida inovadores que permitem tirar das obras toda força de inovação que elas contém, reciprocamente; é apoiando-se nas obras inovadoras que se vai fortificar os novos modos de vida.

Dessa forma, um dos critérios para considerar uma obra de ficção científica como de elevada qualidade é verificar em que medida ela inova ao lançar luzes sobre as questões que afetam nosso modo de vida, questões essas, pelo próprio caráter do gênero, vinculadas à ciência e à tecnologia. Tais obras acabam por se tornar uma referência simbólica, repercutindo em diversos âmbitos da cultura humana. 
Piassi, L. P.

\section{A ficção científica no ensino de ciências}

No ensino formal, o uso da ficção científica em sala de aula vem sendo sugerido por diversos professores e pesquisadores. Um dos principais proponentes desse tipo de utilização parece ser Leroy Dubeck, em seus diversos artigos publicados a respeito, normalmente versando sobre a utilização de um filme para ilustrar ou levantar questionamentos a respeito de determinados tópicos de ciência. Para esse autor,

[...] o uso de tais filmes podem ajudar os estudantes a aprender ciência de várias maneiras:

1. Os princípios científicos ilustrados ou violados em um filme serão melhor entendidos pelos estudantes do que se fossem apresentados apenas através das abordagens tradicionais. As fórmulas matemáticas e as descrições dos livros-texto frequentemente são confusas. É mais fácil, para os estudantes, entenderem princípios científicos abstratos quando eles são diretamente visualizados. Em suma, os filmes podem fazer o abstrato compreensível de uma forma atrativa.

2. Exibir um filme e discuti-lo aperfeiçoa o entendimento da ciência tanto como um processo racional quanto como um processo de descoberta. Isso auxilia os estudantes a aprenderem abordagens científicas de problemas e a identificare abordagens pseudocientíficas.

3. Os filmes, ao apresentarem a ciência em uma situação dramática e relacioná-la a questões socialmente significantes, tornam a ciência mais relevante aos estudantes.

4. Os filmes, muitas vezes, lidam com os temas científicos sob a perspectiva de muitas disciplinas. Consequentemente, o estudante nãocientista vivencia a ciência em um contexto interdisciplinar. Isso é valioso porque, no "mundo real", as situações raramente são restritas a uma única disciplina (DUBECK et al., 1993, p. 47, tradução nossa).

Nesse artigo, o autor dá como exemplo o uso do filme '2001: uma odisseia no espaço' (2001), sugerindo empregá-lo para discutir as leis da conservação do momento linear e angular e "como a 'gravidade artificial' pode ser criada no espaço" (DUBECK et al., 1993, p. 48), através da estação espacial girante, criação esta, aliás, para a qual dois outros autores, Borgwald e Schreiner (1993), propõem uma interessante análise física quantitativa a ser realizada em sala de aula. Em outro artigo, Dubeck et al. (1990) desenvolvem mais detalhadamente uma atividade com o filme 'Forbiddenplanet' (2001), sugerindo seu uso na discussão de conceitos ligados à conservação da energia, radiação e gravidade, além de questões de engenharia. Em um outro trabalho (DUBCEK; TATLOW, 1998), propõem o uso do filme 'Impacto profundo' (1998) para discutir a possibilidade de uma colisão de um cometa ou asteroide com a Terra, e suas consequências.

Seguindo uma linha similar, Freudenrich (2000) defende o uso da ficção científica em sala de aula. Segundo ele, "uma das maneiras de estimular e manter o interesse em ciência é proporcionar um ambiente de contextualização para o aprendizado, e uma das mais poderosas 
A ficção científica e o estranhamento cognitivo ...

e flexíveis contextualizações é o estudo da ficção científica" (FREUDENRICH, 2000, p. 42). O autor relata o uso do filme '2010: o ano em que faremos contato' (1984) em uma atividade de três semanas com uma turma de estudantes de sétima a nona série do correspondente ao Ensino Fundamental. Nesta atividade, ele explora conteúdos como: as leis de Newton, momento, impulso e outros tópicos de física. Além disso, prossegue o curso com a leitura do livro 'Mars', de Ben Bova (1993), a partir do qual desenvolve diversos tópicos relacionados ao planeta Marte. Ao longo do artigo, o autor dá sugestões de um grande número de livros e filmes que poderiam ser usados em aulas e defende que a ficção científica é um recurso particularmente interessante em cursos de ciência integrada (FREUDENRICH, 2000, p. 45). Para o ensino secundário, Dark (2005) descreve uma atividade com o filme 'Armageddon' (1998), com o estudo de conceitos ligados à gravitação e à física orbital, incluindo cálculos para evitar que um asteroide do tamanho do estado do Texas colida com a Terra (DARK, 2005, p. 464). Para essa autora, o uso de filmes de ficção científica em aulas de física se justifica por diversas razões:

Filmes são um recurso didático visual. Estudantes de física introdutória mostram um forte interesse em participar de atividades envolvendo filmes em contraposição a sessões de resolução de problemas em grupo. Finalmente, essas atividades encorajam o pensamento criativo e podem ser usadas para desenvolver habilidades de escrita. (DARK, 2005, p. 463, tradução nossa)

Também com propostas para o nível secundário, Southwork (1987), ao invés de filmes, faz uso de contos de ficção científica. Ele propôs a leitura dos contos 'The last question' e 'Billiard ball' de Isaac Asimov² (1986), e um de Richard Lupoff (1975), denominado 'Saltzman's madness', para discutir tópicos de física moderna. Martin-Diaz et al. (1992) também propõem o uso de contos. Em seu artigo, mostram uma atividade dirigida ao ensino secundário que emprega o conto 'Maelstron II'3 $^{\text {'3 }}$ de Arthur C. Clarke (1990), que serve de motivador para diversas análises quantitativas envolvendo cinemática e dinâmica orbital. Dizem os autores:

Acreditamos fortemente que a ficção científica pode ser uma ferramenta muito útil para nos ajudar a atingir alguns objetivos na educação científica como aumentar a motivação e o interesse dos estudantes, desenvolver atitudes positivas em relação à ciência, promover a criatividade dos estudantes e uma mudança crítica de mentalidade, etc. (MARTIN-DIAZ et al., 1992, p. 22, tradução nossa)

Andrew Fraknoi (2003) também defende o uso da ficção científica escrita, e argumenta que vários dos melhores escritores de ficção científica possuem sólida formação científica.

\footnotetext{
${ }^{2}$ Publicados no Brasil, respectivamente, como 'A última questão' e 'A bola de bilhar', na coletânea 'Sonhos de robô'.

${ }^{3}$ Publicado no Brasil na coletânea 'O vento solar' (CLARKE, 1976).
} 
Piassi, L. P.

A partir daí, fornece um catálogo geral de autores e obras interessantes e dá sugestões práticas de abordagem em sala de aula:

1. Quando se estiver abordando um tema particular de ciências, simplesmente descrever uma história de ficção científica que lance luz sobre aquele tópico. [...]

2. Atribuir a um aluno ou grupo de alunos mais adiantados a tarefa de ler uma história particularmente boa e então relatá-la à classe [...] logo após o tópico de ciência que a história envolve ser coberto. [...]

3. [...] Pegar uma história de ficção cientifica desatualizada ou que utilize ciência incorreta e então fazer com que os alunos discutam quais são os problemas. [...]

4. Atribuir a leitura de uma história curta como tarefa para casa, solicitar aos alunos que pensem a respeito dela e então dividi-los em pequenos grupos para responder questões sobre a história. [...]

5. [...] Fazer com que os estudantes selecionem uma história à sua escolha e façam uma análise da ciência nela presente. [...]

6. Após discutir um certo número de histórias de ficção científica durante o curso de um semestre, pode ser interessante encorajar os estudantes [...] a escrever as suas próprias histórias. (FRAKNOI, 2003, p. 115 , tradução nossa)

Entusiasta da ficção científica no ensino, Fraknoi (2009) mantém, inclusive, uma página na internet com um catálogo de histórias de ficção científica com "boa física e astronomia”, ou seja, obras em que a ciência retratada estaria em razoável acordo com os princípios e procedimentos da física e da astronomia reais. Diz o autor:

Hoje, mais do que nunca, há uma grande quantidade de boa ficção científica sendo escrita por autores que possuem ou formação avançada ou bom repertório em ciência. Mesmo um número de autores bem conhecidos sem formação científica levam sua ciência a sério o suficiente para fazer de seus trabalhos uma leitura de valor. Algumas das melhores histórias envolvem tanto a sensibilidade da escrita literária quanto a extrapolação razoável a partir das descobertas científicas de hoje. (FRAKNOI, 2003, p. 112, tradução nossa)

Uma abordagem diferente é feita por Neves et al. (2000), que utilizam filmes de ficção científica para discutir a história e a evolução dos conceitos científicos, e não apenas os conceitos em si. Através de um paralelo entre filmes de ficção científica espaciais, como '2001: uma odisseia no espaço' (2001) e 'Star wars' (2006), os autores abordam a evolução histórica das ideias sobre movimento, partindo da física aristotélica até Galileu e Newton. Outros autores também vão além da pura abordagem de conceitos. Um exemplo vem de Nauman e Shaw (1994), que propõem a leitura de histórias de ficção científica, nas várias séries do correspondente ao Ensino Fundamental, como forma de despertar o interesse dos estudantes por ciên- 
cia. Em seu artigo, elencam diversos títulos, sugerindo as séries a que são adequados e dando uma breve descrição de cada um deles. $\mathrm{Na}$ discussão dos textos, há uma ênfase não apenas para questões conceituais, mas, também, para problemas sociais envolvendo a ciência e a tecnologia. Para esses autores:

O gênero pode fornecer para as crianças e igualmente para os adultos uma janela para o futuro, um meio de prever como a vida poderia ser em alguma data no futuro. O estudo da história conta-nos como eventos no passado afetaram o presente; a ficção científica nos dá uma ideia de como as decisões que fazemos agora, pode afetar nossas vidas no futuro. (NAUMAN; SHAW, 1994, p. 18, tradução nossa)

Outras autoras, Shaw e Dybdahl (2000), preocupam-se com a forma com que a ciência é expressa na mídia em geral - e na ficção científica em particular - e propõem um uso mais generalizado desses produtos da mídia em sala de aula. Para elas:

Adicionalmente ao aprendizado de ciência nessa fonte formal [a escola], as crianças aprendem ciência em fontes informais. Esse aprendizado inclui seus contatos com a ciência na mídia não impressa, como os filmes, os programas e comerciais de televisão, e a mídia impressa, como os jornais, revistas e livros. As interações entre o aprendizado formal e o informal de ciência pode ser complexo. Às vezes o aprendizado formal pode auxiliar o currículo formal; em outras vezes pode entrar em conflito com ele. Como as crianças irão travar contato com a ciência por ambas as fontes, se os professores puderem deliberadamente planejar o entrelaçamento das duas, serão capazes de melhorar a qualidade do aprendizado de seus alunos. (SHAW; DYBDAHL, 2000, p. 22, tradução nossa)

Essas autoras colocam, entre as atividades propostas, algumas apresentadas como abordando questões de ciência, tecnologia e sociedade (CTS) (SHAW; DYBDAHL, 2000, p. 27). Também preocupado com as questões sociais ligadas à ciência, Rose (2003, p. 289, tradução nossa) é explícito no título do trabalho: 'como ensinar biologia usando a ciência filmográfica da clonagem de pessoas, ressuscitação de mortos e a combinação de moscas com humanos'. O autor aborda a discussão de diversos filmes. O trabalho de sala de aula proposto é particularmente interessante por seus objetivos, assim explicados pelo autor:

Como professor de ciência, sempre estive desafiado a encontrar formas de engajar estudantes não ligados à ciência no aprendizado de como e porque a ciência é realizada. Com esse fim, desenvolvi um curso de ciência geral denominado 'A Biologia nos Filmes', que emprega filmes baseados na biologia como um ponto de partida para discutir idéias fundamentais, técnicas e implicações sociais de tópicos tais como a clonagem humana, manipulação genética, origens do ho- 
Piassi, L. P.

mem e evolução, inteligência artificial e recombinação de animais. (ROSE, 2003, p. 289, tradução nossa)

Brake e Thornton (2003), por sua vez, descrevem um curso sobre ciência e ficção científica oferecido na Universidade de Glamorgan. Esses autores dão destaque específico para a relação entre "ciência, cultura e sociedade" (BRAKE; THORNTON, 2003, p. 31), afirmando que o gênero sempre foi empregado no sentido de examinar as relações entre ciência, tecnologia e sociedade. Afirmam os autores:

Comercialmente a ficção científica possui uma história impressionante e, visto que para muitas pessoas a principal exposição à ciência se dá através da ficção científica, tanto as visões sobre os cientistas quanto as relativas à natureza da atividade científica são de crucial importância para questões relacionadas às atitudes públicas perante a ciência. (BRAKE; THORNTON, 2003, p. 32, tradução nossa)

Aqui vemos a preocupação de alguns autores com as questões socioculturais ligadas à ciência, autores estes que identificam, na ficção científica, um canal privilegiado para a abordagem destes temas. Para estes autores, trazer o universo da ficção científica para a sala de aula significa propiciar oportunidades de questionamento a respeito não apenas de fenômenos e leis científicas, mas, em muitos casos, da própria natureza da atividade científica e de sua relação com a sociedade. Incorporar a ficção científica no ensino da ciência faz sentido se pudermos aproveitar todo esse potencial de inovação e questionamento, as características próprias ao gênero, que são aquilo que ele tem de melhor a oferecer aos professores de ciência. É necessário partir de uma concepção de conteúdo escolar mais ampla do que o mero ensino de conceitos e leis da ciência. Com isso, não queremos dizer que tais conhecimentos não sejam importantes. Ao contrário, eles são o próprio produto da ciência e sua razão de ser, e o que chamamos de conhecimento científico, afinal, é o resultado consensual que reside nessa esfera e que é o que dá à ciência o valor que ela possui.

Assim, por um lado, defendemos que um curso de ciência de formação geral - como no Ensino Médio e Fundamental - deva ser construído em função dos conceitos, leis e fenômenos e de suas articulações lógicas. Por outro lado, embora a estruturação dos conteúdos deva ser feita a partir da estrutura conceitual da ciência, isso não significa restringir-se a esta esfera, mas apenas que o conteúdo de ensino se estrutura a partir dela, mesmo quando os conceitos e as leis não são o foco central da aula. Se acreditamos que um aluno não deveria sair do Ensino Básico sem ter alguma vez travado contato, por exemplo, com a discussão sobre as armas nucleares temos de pensar, também, que aspectos dessa discussão precisam ser levados à sala de aula e qual é o papel específico que cabe ao professor de ciência neste processo. Como as questões sociais não estão desvinculadas dos aspectos técnico-científicos, é necessário que o professor com formação científica tenha de participar desse debate, que é naturalmente, interdisciplinar. A ficção científica, mais do que se fixar no aspecto das leis naturais envolvidas na bomba atômica ou de qualquer outro tema, suscita um debate sobre as implicações sociais das possíveis descobertas, invenções e fenômenos concebíveis. Põe em questão a tecnologia, que é fundamental na vida, que está visceralmente ligada à ciência. O uso da ficção 
científica é um meio de tratar de questões sociais e tecnológicas sem ensinar tecnologia, sem converter o ensino de ciências em um curso de tecnologia, mas enfocando-o como uma reflexão sobre o presente para um pensar-agir no futuro.

Nesta visão, a ficção científica em sala de aula não é mais um mero artifício ou método estimulante, mas um elemento cultural que, por suas características próprias, possui um potencial privilegiado na abordagem de questões científicas. Sendo assim, como podemos elaborar propostas ou atividades que possam se beneficiar da ficção científica naquilo que the é próprio e que a torna especialmente interessante, suplantando concepções ingênuas em relação a obras de ficção?

\section{A ficção científica e o conhecimento científico}

O maior consenso dos autores que se debruçaram sobre a questão da delimitação do gênero da ficção científica talvez seja justamente a enorme dificuldade de se realizar tal delimitação. Todos, porém, acabam, de uma forma ou de outra, buscando estabelecer a fronteira entre o que é e o que não é ficção científica. Embora, para os nossos propósitos, a delimitação precisa dessa fronteira tenha importância secundária, o processo pelo qual os diversos autores procuraram estabelecer essa fronteira evidencia as relações entre a ficção científica e o saber científico, esse, sim, um aspecto fundamental no que se refere ao seu uso didático.

Isaac Asimov (1984), o famoso escritor, tenta fazer a delimitação situando a ficção científica dentro de um gênero mais geral, que ele denomina ficção surrealista, definindo-a como retratando "fatos que se verificam em ambientes sociais não existentes na atualidade e que jamais existiram em épocas anteriores" (ASIMOV, 1984, p. 16). A partir disso, especifica para a ficção científica:

Os acontecimentos supra-reais da história, na ficção científica, podem ser concebivelmente derivados do nosso próprio meio social, mediante adequadas mudanças ao nível da ciência e da tecnologia. (ASIMOV, 1984, p.16)

David Allen (1976) também procura uma definição geral para a ficção científica, mas procura situá-la dentro da literatura e explicita alguns elementos distintos de Asimov (1984):

Subgênero da ficção em prosa que é distinguido de outros tipos de ficção pela presença de uma extrapolação dos efeitos humanos de uma ciência extrapolada, definida em termos gerais, assim como pela presença de 'engenhos' produzidos pela tecnologia resultante de ciências extrapoladas. (ALLEN, 1976, p. 235)

Allen (1976), portanto, distingue a ficção científica dos outros subgêneros da ficção em prosa, através de uma caracterização de conteúdo. O que Allen (1976) define por "ciência extrapolada" é um conhecimento implícito derivado da ciência. Assim, entendemos o termo "ciência extrapolada" como uma categoria mais geral, que engloba qualquer forma de utiliza- 
ção de ideias científicas para a produção do conteúdo veiculado no texto. A ciência extrapolada em si não é conteúdo da história, mas um implícito do processo de construção dos elementos, por exemplo, os engenhos. Quanto aos "efeitos humanos", que também são extrapolados, podemos supor que são resultados de processos, estes, sim, retratados no conteúdo da obra. Além disso, são humanos os efeitos, sendo, portanto, de caráter social, e não natural.

Umberto Eco (1989) segue um caminho distinto, que permite situar melhor a ficção científica dentro de um espectro mais amplo e extrair o que é mais próprio dela. O crítico italiano estabelece quatro caminhos possíveis para a literatura fantástica (ECO, 1989, p.167): a alotopia, a utopia, a ucronia e a metatopia e metacronia. O primeiro caminho, a alotopia, constitui-se na construção de um ambiente próprio, desvinculado, no nível do discurso, do que Asimov (1984) chama de "nosso próprio meio". A utopia, por outro lado, é, nas palavras de Eco (1989, p. 167), uma "projeção, representação de uma sociedade ideal", mas é retratada como sendo um local e um tempo, muitas vezes não muito definido, que não constitui em si um outro mundo com leis próprias, e sim como um possível imaginado do nosso próprio mundo, modificado em certos aspectos, "em sentido caricatural, como deformação irônica de nossa realidade" (ECO, 1989, p.167). A ficção científica se vale do modelo utópico para contar suas histórias, porém empregando um processo pelo qual, segundo Eco (1989, p. 168):

[...] o mundo paralelo é sempre justificado por rasgos, desfiamentos no tecido espaço-temporal, enquanto na utopia clássica ele é simplesmente um não-lugar dificilmente identificado (talvez passado e desapercebido) do nosso próprio mundo físico.

O próximo caminho mencionado por Eco (1989, p. 168) é a ucronia, representação do "que teria acontecido se o que realmente aconteceu tivesse acontecido de modo diferente". A ficção científica está repleta de obras desse tipo, muito conhecidas como história alternativa. Porém, Eco (1989) defende que a ficção científica encontra seu sentido mais característico na metatopia e na metacronia, onde:

[...] o mundo possível representa uma fase futura do mundo real presente; e por mais que seja estruturalmente diverso do mundo real, o mundo possível é possível (e verossímil) exatamente porque as transformações a que foi submetido nada mais fazem do que completar as linhas de tendência do mundo real. (ECO, 1989, p.168)

Aqui Eco (1989) aproxima-se muito das caracterizações dadas por Allene Asimov. As "transformações que completam linhas de tendência" (ECO, 1989, p. 168) são, a nosso ver, equivalentes à ideia de extrapolação presente na delimitação de Allen. Mas o autor vai além na reflexão a respeito do caráter da ficção científica. O que Eco (1989) enfatiza - e talvez tenha sido pouco explorado pelos dois primeiros autores - é a percepção da ficção científica como um gênero que se avizinha de diversos outros e que encontra características próximas a vários subgêneros que, às vezes, podem ser tomados como ficção científica, às vezes não, dependendo do aspecto que se analise. A partir dessa delimitação que se faz em oposição aos gêneros próximos, Eco (1989) procura encontrar, na ficção científica, algo que lhe é próprio. O aspec- 
to fundamental que Umberto Eco atribui à ficção científica é a presença de um processo de conjectura sobre o mundo real:

Temos science fiction como gênero autônomo quando a especulação contrafactual de um mundo estruturalmente possível é conduzida extrapolando, de algumas linhas de tendência do mundo real, a possibilidade mesma do mundo futurível. Ou seja, a ficção cientifica assume sempre a forma de uma antecipação, e a antecipação assume a forma de uma conjetura formulada a partir de linhas de tendência reais do mundo real. (ECO, 1989, p. 169, grifo do autor)

Aqui, o que percebemos é que todos os elementos que levantamos nas caracterizações da ficção científica - o mundo real, a transformação via extrapolação, a extrapolação fundamentada na racionalidade científica - vêm, na verdade, servir a um processo de especulação a respeito do mundo real, especulação essa que obedece a certos parâmetros de racionalidade típicos do pensamento científico. Para Eco (1989, p. 170), "a boa ficção científica é cientificamente interessante não porque fala de prodígios tecnológicos [...], mas porque se apresenta como um jogo narrativo sobre a própria essência de toda a ciência, isto é, sobre a sua conjeturabilidade". Um caminho de análise semelhante é adotado por outros autores, que chegam a conclusões parecidas. Rabkin (1977, p. 120), por exemplo, diz: "A variação a partir do conhecimento aceito é uma das características definidoras do gênero de ficção científica, e essa é uma característica que podemos usar para subdividir cuidadosamente o gênero para propósitos de análise".

Assim, de certa forma concordando com os demais autores, Rabkin (1977) vê no conceito de variação a chave fundamental, ideia essa que associamos à derivação e mudança de Asimov, à extrapolação de Allene, à transformação de Umberto Eco. Rabkin (1977) chama isso de definição por diferença. Mas, além dessa variação, o autor atribui à ficção científica um aspecto importante, que, embora relacionado, não se confunde com esse primeiro:

O que é importante na definição da ficção científica não são as justaposições de armas de raios e aventais de laboratório, mas os hábitos mentais 'científicos': a ideia de que são paradigmas que controlam nossa visão de todos os fenômenos, que no interior desses paradigmas todos os problemas normais podem ser resolvidos, e que as ocorrências anormais devem ou serem explicadas ou iniciarem a busca por um paradigma melhor (usualmente mais inclusivo). (RABKIN, 1977, p. 121, tradução nossa)

Rabkin (1977) atribui, como um dos marcos definidores da ficção científica, a perspectiva do discurso que pressupõe a racionalidade científica, e afirma que isso é mais importante do que traços do conteúdo geralmente associados ao gênero, como os raios e os aventais. DarkoSuvin (1984) segue uma linha semelhante, mas dá destaque central à noção de novum, e afirma que "pode-se diferenciar a FC [ficção científica] pelo domínio ou hegemonia narrativa de um 'novum' (novidade, inovação) validado mediante a lógica cognoscitiva" (SUVIN, 1984, 
p. 94, tradução nossa). Para o autor, essa "inovação postulada pode apresentar graus muito diferentes de magnitude" (SUVIN, 1984, p. 95, tradução nossa), indo desde o menor grau de uma invenção ou aparato, passando pelos agentes ou por "relações basicamente novas e desconhecidas no ambiente do autor" (SUVIN, 1984, p. 95, tradução nossa). Este novum, a exemplo do que vemos na citação de Rabkin (1977), deve ser entendido não somente a partir de novos aparatos técnicos ou de seres estranhos, ou seja, dos elementos superficiais do conteúdo da obra, mas, sobretudo, da lógica de fundo científico, da disposição mental que o discurso da obra induz.

A construção do discurso da ficção científica, através da derivação, é pautada, a nosso ver, por uma conjecturabilidade que se inscreve dentro dos limites de uma racionalidade lógicocausal pautada pela exploração dos efeitos humanos decorrentes da colocação do leitor em frente ao novum. O efeito literário da obra em si decorre da apresentação desse novum como disparador imediato das conjecturas a respeito dos efeitos humanos, mas sempre nos limites da racionalidade lógico-causal. A continuidade espaço-temporal, por outro lado, pode tanto ser cuidadosamente preservada como, também, pode ser levada aos limites da ruptura, com consequências distintas. Um aspecto fundamental desse novum é destacado por Causo (2003), o chamado sense of wonder:

\begin{abstract}
"Milagre", "maravilhoso", "sublime" e "sentido de maravilhoso" (sense of wonder) podem ser interpretados como a evolução de um princípio que pressupõe a presença de um fato extraordinário interpenetrando a consciência do real e do cotidiano, causando, em alguma medida, o choque entre o que a consciência admite como parte de sua experiência imediata, e esse algo novo que vem desafiar a experiência. Às vezes chamado de "estranhamento", tal choque está na base de toda a ficção especulativa. (CAUSO, 2003, p. 78)
\end{abstract}

O autor chama a atenção sobre a interessante expressão sense of wonder, que "significa tanto 'maravilhar-se, espantar-se com algo', quanto 'perguntar-se, querer saber deste algo"' (CAUSO, 2003, p. 79). Neste sentido, Suvin (1984, p. 29) chama a atenção para o aspecto de cognição e Peter Nicholls (apud CAUSO, 2003, p. 78) estabelece o conceito de avanço conceitual. Não se trata de mero 'espanto' e 'estranhamento' frente ao incomum, algo que pode bem acontecer em histórias de terror ou fantasia. Trata-se de algo que provoca o estranhamento, mas, além disso, obriga a pensar naquele estranho como uma conjectura plausível e lógica, aplicável ao mundo fora da ficção. A ideia de avanço conceitual dá um passo além, ao propor que o efeito da boa ficção científica é permitir "romper ou substituir paradigmas, ou modos estabelecidos de compreensão do universo" (CAUSO, 2003, p. 83).

$\mathrm{Na}$ ficção científica, há a construção do contrafactual a partir de um fato conhecido cientificamente, contrapondo-se a ele através da apropriação de elementos do discurso científico, seja através do plano da expressão (terminologias, léxicos, imagens), seja através do plano do conteúdo (conceitos, relações, processos de raciocínio) deste discurso. Quando o processo de produção do contrafactual se vale do discurso científico através desse método típico da ficção científica, sempre teremos, no mínimo, uma conjecturabilidade potencial, mesmo quando a conjectura em si não é realizada explicitamente no nível do discurso da obra. 
A ficção científica e o estranhamento cognitivo ...

\section{Conclusões: o que a ficção tem a oferecer à educação?}

Cabe, então, se perguntar como essas características da obra de ficção científica podem ser consideradas quando se pensa em levá-las para a sala de aula. Quais são os aspectos a serem levados em conta e como eles podem se reverter em um processo consciente de elaboração de atividades didáticas? O passo que julgamos fundamental na proposta de levar ficção científica para a sala de aula é investigar caminhos que levem a um processo de problematização, de investigação cultural ativa por parte dos estudantes. Para respondermos a esta, que afinal é a nossa questão fundamental, consideremos a abordagem mais comum, defendida por diversos autores que acabamos de discutir: o uso da ficção científica como motivadora da aprendizagem de conceitos. Em seu famoso livro 'Aprenda física brincando', o autor russo J. Perelman (1970) se vale da ficção científica de sua época e, a respeito dela, diz no prefácio da obra:

Considerando que esta última [a ficção científica] se adapta perfeitamente a livros do gênero deste, recorremos amplamente a exemplos tirados de Júlio Verne, H. G. Wells, Mark Twain e outros escritores porque, além de proporcionar entretenimento a nossos leitores, as fantásticas experiências que eles descrevem podem servir para ilustrar, de modo instrutivo, aulas de Física. (PERELMAN, 1970, p. 15)

Um dos exemplos de que Perelman (1970) se utiliza é o romance 'O homem invisível' de H. G. Wells, incluindo o clássico questionamento "Pode um homem invisível ver?", ao que Perelman (1970, p. 455, grifo do autor) responde: "Se Wells tivesse parado para se fazer essa pergunta antes de escrever sua novela, nós nunca teríamos tido o prazer de ler sua absorvente narrativa. Isso estraga todo o plano porque um homem invisivel tem que ser ... cego!", e prossegue explicando que, se até os olhos são transparentes, possuindo "índice de refração idêntico ao do ar” (PERELMAN, 1970, p. 455), a luz não poderá ser absorvida. Perelman (1970), porém, subestimou os conhecimentos e a engenhosidade de Wells, que foi um dos grandes divulgadores científicos. Ao acordar do sono, após ingerir o elixir, diz o homem invisível de Wells: "Eu estava fraco e sentia fome. Olhei-me no espelho e nada vi senão um pigmento atenuado que permanecia no fundo da retina. Tive que apoiar-me à mesa e encostar a testa no espelho para não cair" (WELLS, 2001, p. 117).

Assim como o gato que o homem invisível usou de cobaia, ele também teve seus olhos parcialmente preservados da invisibilidade, o que lhe preservava igualmente a faculdade da visão. Independentemente dessa imprecisão em relação à obra, o que podemos observar em Perelman (1970) é a interpretação superficial, com uma única preocupação: saber se seria ou não possível a invisibilidade. A nosso ver, ler um romance da categoria de 'O homem invisível' para explorar apenas este pequeno aspecto é uma diminuição radical do valor da obra e de seu potencial pedagógico. Claro que a leitura de um bom romance é sempre bem-vinda. Porém, como atividade didática, se tão pouco for aproveitado, será, ao mesmo tempo, um desperdício da obra e um desperdício do tempo e do esforço despendido em sala de aula. Muitas obras de ficção científica, como já apontamos, foram produzidas tendo em vista, além do prazer com a aventura, essa finalidade didática, do exame superficial dos fenômenos, dos artefatos e das técnicas apresentadas. Esse, certamente, não é o caso das obras de H. G. Wells. 
Piassi, L. P.

Suvin (1984), embora reconheça o valor educativo de obras de ficção científica produzidas com finalidades didáticas, fala dos problemas que isso traz à qualidade literária da obra, sobretudo em sua capacidade de produzir um estranhamento cognitivo:

Exigir da FC [ficção científica] um estranhamento galileano não significa de maneira alguma deixá-la em mãos da vulgarização científica ou até do prognóstico tecnológico, a que ela se dedicou em distintas ocasiões [...]. A tarefa necessária e meritória da popularização pode ser um elemento útil das obras de FC a nível juvenil. Mas inclusive o roman scientifique, como Da Terra à Lua, de Verne - ou o aspecto superficial de O Homem Invisivel, de Wells -, embora sejam forma legítima da FC, constitui uma etapa inferior em seu desenvolvimento. (SUVIN, 1984, p. 32, grifos do autor)

Suvin (1984) fala aqui das "novidades científicas" que pretendem maravilhar o leitor, como o submarino Nautilus de Verne e diversos outros fenômenos e dispositivos produzidos pela imaginação de muitos autores de ficção científica, particularmente Júlio Verne. Para Suvin (1984, p. 33), tais novidades "apresentam uma estrutura de estranhamento transitório, mais específico dos romances policiais do que da FC madura". Nesse trecho, o autor fala do estranhamento galileano referindo-se à peça 'Galileu', de Bertold Brecht; e, citando o próprio Brecht em seu trabalho 'Breve método para o teatro', caracteriza esse estranhamento como uma percepção de algo que, ao mesmo tempo em que é familiar, permitindo-se reconhecer, traz embutido em si algo que o transcende e produz o estranhamento, e que para que alguém possa vivenciá-lo:

[...] necessitará possuir esse olhar neutro com que o grande Galileu observou um candelabro que balançava. Sentiu-se assombrado por aquele movimento pendular, como se não o esperasse e não lograsse compreender o ocorrido; isso the permitiu encontrar as leis que o governavam. (BRECHT apud SUVIN, 1984, p. 29, tradução nossa)

Em outras palavras, Suvin (1984) está falando da capacidade de estabelecer, no leitor, o efeito de assombro profundo que colocará em ação mais do que um deleite efêmero com as maravilhas vindouras, mas, também, o questionamento duradouro sobre as possibilidades da ação humana sobre o mundo natural e social, dadas a partir do conhecimento do mundo natural. Observemos que Suvin (1984) se refere à obra de Julio Verne de forma geral, mas apenas ao "aspecto superficial", ou seja, a uma leitura ingênua de "O homem invisível", de H.G. Wells, apenas como uma mera história curiosa de um homem invisível e das maravilhas da invisibilidade. Como diz Borges (1991), a obra de Wells suscita muito mais do que isso, de forma que, até Perelman (1970), muito mais preocupado com as questões da óptica, não resiste em ensaiar alguns passos mais além:

Wells demonstra com extraordinária lógica e sabedoria que um homem invisível adquire uma força ilimitada. Ele pode entrar em qual- 
quer lugar sem ser notado e roubar qualquer coisa imponentemente. Ardiloso, graças à invisibilidade, ele luta com sucesso contra toda uma turma de homens armados. Conseguindo derrotar todos os que são visíveis, o homem invisível subjugou a população de toda uma cidade. Ardiloso e invulnerável, ele derrota todos os seus oponentes, apesar de suas precauções. (PERELMAN, 1970, p. 453)

Perelman (1970) não prossegue nisso que poderia ser um início de análise mais atenta da obra: o significado dessa personagem, de suas motivações, o que representa o ambiente, a cidade, a narração em primeira pessoa - e, como diz Borges (1991, p. 2), do "simbólico de processos que, de algum modo, são inerentes a todos os destinos humanos". Claro que não podemos desprezar as possibilidades didáticas do exame de superfície e, mesmo, do uso de obras que pareçam não trazer mais do que um deleite efêmero de sensações. Em outras palavras, não podemos a priori desconsiderar - do ponto de vista do potencial educativo - uma obra apenas porque ela é um blockbuster hollywoodiano aparentemente "sem conteúdo". Porém, menos ainda, podemos desprezar as possibilidades da cognição (SUVIN, 1984) e do poder heurístico (RABKIN, 1977) mais profundos, que são os efeitos centrais das melhores obras de ficção científica, deixando essas possibilidades em favor de engenhos espetaculares e superpoderes maravilhosos. Ao contrário, são justamente essas características que permitem a essas obras reivindicar um lugar de destaque naquilo que Snyders (1988, p. 68) chama de cultura elaborada, com a "força da inovação que elas contêm". Aqui cabe a consideração da ideia de continuidade-ruptura que, segundo Snyders (1988, p. 87), "é dizer que a proposta vai realmente tocar os interessados porque ela guarda parentesco com que eles são, com que eles gostam”, e prossegue:

A satisfação que lhes propõem a cultura elaborada, é essa satisfação que vocês começaram a viver na cultura primeira, o que você sente confusa, contraditoriamente, lufadas de otimismo, de confiança em si próprio, no mundo, no amor - e isso pode tornar-se mais sólido na medida em que os elementos de satisfação não vão mais ser contrariados por cem outras infiltrações. (SNYDERS, 1988, p. 88)

E aqui chegamos ao ponto mais fundamental: o prazer da leitura, a apreciação da obra em sua força artística tem de ser a base fundamental do trabalho. Ficamos diante de uma tensão fundamental - escolher as obras. Ao mesmo tempo, precisamos ter um olhar de crítico e de professor: para reconhecer os méritos da obra em levar os alunos a reflexões que, ao mesmo tempo, façam sentido para eles, mas que, também, os levem a dar passos adiante. Se adotarmos uma postura elitista, só usaremos cult-movies e romances ultraprofundos, que podem simplesmente fazer os alunos se desinteressarem. Por outro lado, se formos condescendentes, corremos o risco de subestimar a capacidade dos estudantes de apreciar grandes obras. Temos de escolher obras que digam coisas inovadoras e transformadoras, mas não de forma obscura demais aos alunos, nem de forma tão evidente e óbvia que não exija qualquer esforço interpretativo por parte deles. Ao trazer as obras para o contexto da sala de aula, o professor pode também incentivar os estudantes a procurarem seus próprios interesses dentro da ficção científica, sugerindo obras e autores de seu interesse, e confrontando as visões de mundo e as 
Piassi, L. P.

técnicas narrativas em sua relação com o conhecimento científico. Isso, certamente, ampliará o universo de possibilidades, que podem, inclusive, envolver outras formas e suportes de expressão, como: os quadrinhos, os videogames ou os jogos de interpretação de papéis (RPG), por exemplo.

De uma forma ou de outra, é justamente na sensação estranha e prazerosa, que nos permite descobrir coisas novas a cada leitura e que nos induz a querer falar, a conversar com os outros sobre aquele filme ou livro, que encontramos a matéria-prima da dinâmica que uma obra é capaz de proporcionar. E é também no processo que leva o estudante a aprender a identificar, apreciar e analisar, cada vez com mais senso crítico e exigência, as obras que lhes apresentamos que está o avanço representado pelo processo de continuidade-ruptura de que nos fala Snyders (1988), desde a cultura primeira até a cultura elaborada.

\section{Referências}

2001: uma odisseia no espaço. Direção: S. Kubrick. Intérpretes: Keir Dullea; Gary

Lockwood. Vídeo. [S.l.]: Warner, 2001. 1 DVD (148 min), son., color.

2010: o ano em que faremos contato. Direção: P. Hyams. Intérpretes: Roy Scheider; John Lithgow e outros. [S.1.]: Warner, 1984. 1 DVD (116 min), son., color.

ALLEN, L. D. No mundo da ficção científica. São Paulo: Summus, 1976.

ARMAGEDDON. Direção: Michael Bay. Intérpretes: Bruce Willis; Billy Bob Thornton; Ben Affleck e outros. Roteiro: J. J. Abrams, Jonathan Hensleigh, Tony Gilroy e Robert Towne. [S.l.]: Disney: Buena Vista, 1998. 1DVD (151 min), son., color.

ASIMOV, I. No mundo da ficção científica. Rio de Janeiro: Francisco Alves, 1984.

Para onde vamos? São Paulo: Hemus, 1979.

. Robot dreams. New York: Ace Books, 1986.

AUGUSTO, S. Space-comics: um esboço histórico. In: MOYA, A. Shazam! 3. ed. São Paulo: Perspectiva, 1977. p. 183-195.

BORGES, J. L. O primeiro Wells. In: WELLS, H. G. A máquina do tempo. 4. ed. Rio de Janeiro: Francisco Alves, 1991. p. 1-5.

BORGWALD, J. M.; SCHREINER, G. Classroom analysis of rotating space vehicles in 2001: a space odyssey. PhysicsTeacher, College Park, v. 31, n. 7, p. 406-409, 1993.

BOVA, B. Mars. New York: Bantam Spectra, 1993.

BRAKE, M.; THORNTON, R. Science fiction in the classroom. Physics Education, Bristol, v. 38, n. 1, p. 31-34, 2003. 
A ficção científica e o estranhamento cognitivo ...

CARD, O. S. Um planeta chamado traição. Rio de Janeiro: Record, 1993.

CAUSO, R. S. Fiç̧ão científica, fantasia e horror no Brasil: 1875 a 1950. Belo

Horizonte: Editora UFMG, 2003.

CLARKE, A. C. The wind from the sun. London: Vista, 1990.

O vento solar. São Paulo: Círculo do Livro, 1976.

DARK, M. Using science fiction movies in introductory physics. Physics Teacher, College Park, v. 43, n. 7, p. 463-165, 2005.

DUBECK, L. W. et al. Science fiction aids science teaching. Physics Teacher, College Park, v. 43, n. 7, p. 316-319, 1990.

Finding facts in science fiction films. The Science Teacher, Arlington, v. 60, n. 4, p. 46-48, 1993.

DUBECK, L. W.; TATLOW, R. Sci-fi in the classroom: making a "Deep impact" on young people's interest in science. Mercury, San Francisco, v. 27, n. 6, p. 24-28, 1998.

ECO, U. Sobre o espelho e outros ensaios. Rio de Janeiro: Nova Fronteira, 1989.

FORBIDDEN planet. Direção F. M. Wilcox. Intérpretes: Walter Pidgeon; Anne Francis e outros. [S.1.]: Warner, 2001. 1 DVD (98 min), son. color.

FRAKNOI, A. Science fiction stories with good astronomy $\&$ physics: a topical index. San Francisco: Astronomical Society of the Pacific, 2009. Disponível em <http://

www.astrosociety.org/edu/resources/scifi.html>. Acesso em: 30 maio 2011.

Teaching astronomy with science fiction: a resource guide. Astronomy Education Review, Tucson, v. 1, n. 2, p. 112-119, jul. 2002 / jan. 2003.

FREUDENRICH, C. C. Sci-fi science: using science fiction to set context for learning science. The Science Teacher, Arlington, v. 67, n. 8, p. 42-45, 2000.

HEMÉRY, D. et al. Uma história da energia. Brasília: Editora Universidade de Brasília, 1993.

IMPACTO profundo. Direção: M. Leder. Intérpretes: Robert Duvall; Téa Leoni e outros. [S.l.]: Paramount, 1998. 1 DVD (121 min), son., color.

JORNADA nas estrelas: a série original. Direção: G. Rondeberry. Intérpretes: William Shatner; Leonard Nimoy e outros. [S.1.]: Paramount, 2005. 1 DVD (1.458 min.), son. color.

LUPOFF, R. Saltzman'smadness. In: ELWOOD, R. Future corruption. New York: Warner, 1975. p. 9-42.

MARTIN-DIAZ, M . J. et al. Science fiction comes into the classroom: Maelstrom II. Physics Education, Bristol, v. 27, n. 1, p. 18-23, 1992.

NAUMAN, A. K.; SHAW, E. Sparking science interest through literature: sci-fi science.

Science Activities, Philadelphia, v. 31, n. 3, p. 18-20, 1994. 
Piassi, L. P.

NEVES, M. C. D. et al. Science fiction in physics teaching: improvement of science education and history of science via informal strategies of teaching. Recen: revista ciências exatas e naturais, Santa Cruz, v.1, n.2, p. 91-101, 2000.

OLIVEIRA, F. R. A ficção científica e a questão da subjetividade homem-máquina. ComCiência: revista eletrônica de jornalismo científico, Campinas, n. 59, out. 2004. Disponível em: < http://www.comciencia.br/reportagens/2004/10/08.shtml>. Acesso em: 29 maio 2011.

PARRINDER, P. Science fiction: it's criticism and teaching. Londres: Methuen, 1980.

PERELMAN, J. Aprenda física brincando. São Paulo: Hemus, 1970.

PIASSI, L. P. C. Contatos: a ficção científica no ensino de ciências em um contexto sociocultural. 2007. 453 f. Tese (Doutorado) - Faculdade de Educação, Universidade de São Paulo, São Paulo, 2007.

PINTO, G. A. (Org.). Divulgação científica e práticas educativas. Curitiba: CRV, 2010.

RABKIN, E. The fantastic in literature. New Jersey: Princenton University, 1977.

ROSE, C. How to teach biology using the movie science of cloning people, resurrecting the dead and combining flies and humans. Public Understanding of Science, Newbury Park, v. 12 , n. 3, p. 289-296, 2003

SHAW, D.; DYBDAHL, C. S. Science and the popular media. Science Activities, Philadelphia, v. 37, n. 2, p. 22-31, 2000.

SHELLEY, M. Frankenstein ou o moderno Prometeu. São Paulo: Círculo do Livro, 1973.

SNYDERS, G. A alegria na escola. São Paulo: Manole, 1988.

SOUTHWORTH, T. Modern physics and science fiction: a mini-unit for high school physics. The Physics Teacher, College Park, v. 25, n.02, p. 90-91, 1987.

STAR wars episódio IV: a nova esperança. Direção: G. Lucas. Intérpretes: Mark Hammil; Harrison Ford e outros. [S.l.]: Fox, 2006. 1 DVD (121 min), son., color.

SUVIN, D. Metamorfosis de la ciencia ficción: sobre la poética y la história de un género literario. Cidade do México: Fondo de Cultura Económica, 1984.

VERNE, J. 20.000 léguas submarinas. São Paulo: Martin-Claret, 2003.

. Viagem ao centro da Terra. São Paulo: Martin-Claret, 2004.

WELLS, H.G. A guerra dos mundos. São Paulo: Nova Alexandria, 2000.

A máquina do tempo. 4. ed. Rio de Janeiro: Francisco Alves, 1991.

O homem invisível. São Paulo: Nova Alexandria, 2001.

Artigo recebido em 02/06/12. Aceito em 18/08/12.

168

Ciência \&̊ Educacão, v. 19, n. 1, p. 151-168, 2013 